\title{
Development of a 300-kV Marx generator and its application to drive a relativistic electron beam
}

\author{
Y CHOYAL, LALIT GUPTA, PREETI VYAS, \\ PRASAD DESHPANDE, ANAMIKA CHATURVEDI, \\ $\mathrm{K} \mathrm{C} \mathrm{MITTAL}^{+}$and K P MAHESHWARI \\ School of Physics, Devi Ahilya Vishwavidyalaya, Indore 452 001, India \\ ${ }^{+}$Accelerator and Pulse Power Division, Bhabha Atomic Research Centre, \\ Mumbai 400 085, India \\ e-mail: ychoyal.sop@dauniv.ac.in; lalitdavv@yahoo.co.in; \\ k_p_maheshwari@rediffmail.com
}

MS received 11 April 2005; revised 8 August 2005

\begin{abstract}
We have indigenously developed a twenty-stage vertical structure type Marx generator. At a matched load of $90-100 \Omega$, for $25 \mathrm{kV} \mathrm{DC}$ charging, an output voltage pulse of $230 \mathrm{kV}$, and duration $150 \mathrm{~ns}$ is obtained. This voltage pulse is applied to a relativistic electron beam (REB) planar diode. For a cathodeanode gap of $7.5 \mathrm{~mm}$, an REB having beam voltage $160 \mathrm{kV}$ and duration $150 \mathrm{~ns}$ is obtained. Brass as well as aluminum explosive electron emission-type cathodes have been used.
\end{abstract}

Keywords. Relativistic electron beam; Marx generator; high-voltage pulse technology.

\section{Introduction}

The Marx generator is the simplest and most widely used high voltage pulse generation device. The basic principle involved is to charge a set of capacitors in parallel and then discharge them in series (Pai \& Zhang 1989). A typical Marx generator consists of an $N$ number of modules. Each module consists of two resistors $\mathrm{R}$, a capacitor $\mathrm{C}$ and a switch in the form of a spark gap (SG). All the modules are stacked together such that as long as the SGs are non-conducting, all the capacitors are charged in parallel upto a voltage $V$ through the charging resistors R's by a DC charging power supply. Once all the C's get fully charged, switching is induced by triggering the first SG. This action not only brings the first and the second capacitors in series, it also makes the remaining SGs overvolted, causing their self-breakdown. All the capacitors, each at $\mathrm{V}$ potential, are now in series; the impulse voltage, which can have a maximum value of $\mathrm{NV}$ (where $\mathrm{N}$ is the number of stages), ultimately decays through the load $R_{L}$ and Marx resistor R's. A typical Marx circuit with resistive load is depicted in figure 1.

In this paper, we report development of a 20-stage Marx generator (MG) that has been tested for delivering $230 \mathrm{kV}, 150 \mathrm{~ns}$ voltage pulse on a matched load of 90-100 $\Omega$ when the 


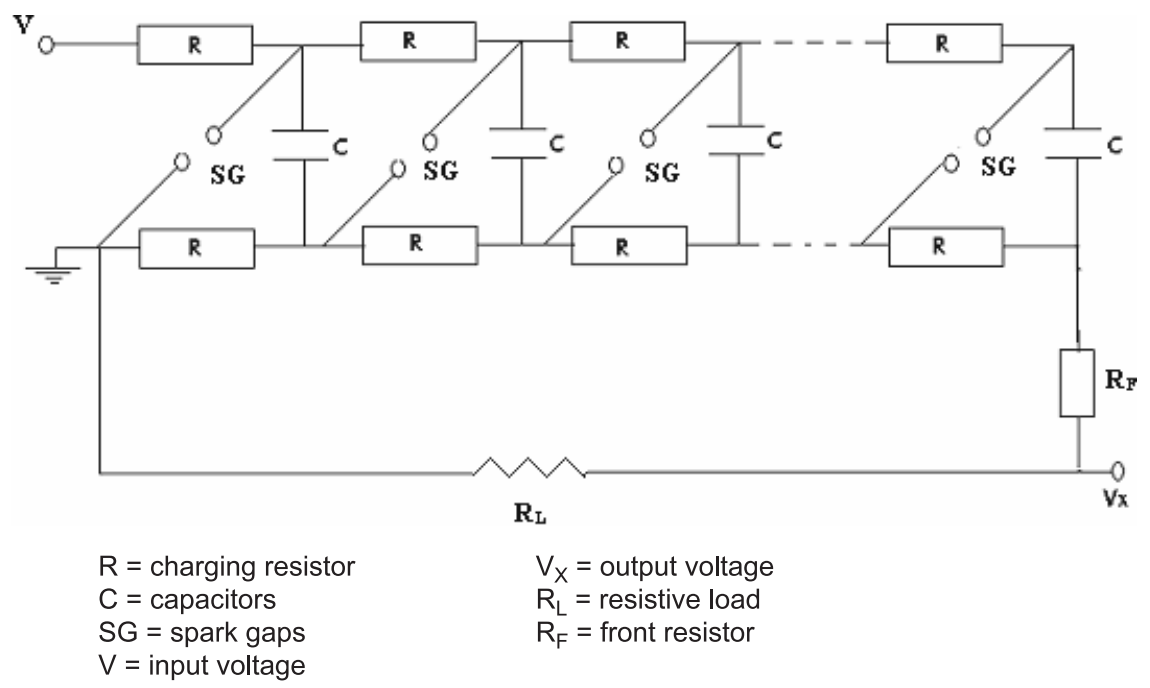

Figure 1. Circuit diagram of Marx generator.

DC charging is limited to $25 \mathrm{kV}$. The maximum pulse power is about $600 \mathrm{MW}$. The impulse voltage from the Marx generator is well suited for direct generation of a relativistic electron beam (REB) as well as for driving narrow band microwave devices such as backward wave oscillator (BWO) (Granatstein \& Alexeff 1987).

Specifically, in $\S 2$ we describe the development of the Marx generator, and in $\S 3$, we discuss REB generation. In $\S 4$, we present the experimental results.

\section{Development of $300 \mathrm{kV}$ Marx generator}

The Marx generator developed at our University laboratory can deliver an output voltage pulse, which has a maximum voltage rating of $300 \mathrm{kV}$ on matched load, energy $180 \mathrm{~J}$ and pulse duration $150 \mathrm{~ns}$ for $30 \mathrm{kV}$ DC charging. Table 1 depicts the specifications of the Marx. There are 20 Marx stages assembled by stacking one over the other in the vertical towering shape. Each stage is made up of one 21-nF capacitor, one SG and two non-inductive resistors having a value of $50 \Omega$ each. The capacitor of each stage is charged by a DC power supply $(0-30 \mathrm{kV}, 20 \mathrm{~mA})$. Capacitor in each module is mounted on a horizontal perspex sheet. The

Table 1. Specifications of the developed Marx generator.

\begin{tabular}{ll}
\hline Charging voltage & $0-30 \mathrm{kV}$ DC \\
Number of capacitors used in Marx $(N)$ & 20 \\
Capacitance of each capacitor & $21-\mathrm{nF}$ \\
Diameter of spark gap (SG) & $15 \mathrm{~mm}$ \\
Resistance (of each tail resistor $R)$ & $50 \Omega$ \\
Total energy stored in Marx & 180 joules \\
Output voltage on matched load & $\sim 300 \mathrm{kV}$ \\
Pulse duration & $\sim 150 \mathrm{~ns}$ \\
\hline
\end{tabular}


lowest stage has a triggered SG which is closed by a $6 \mathrm{kV}$ pulse obtained with the help of a pulse transformer. SGs in each stage are aligned in line-of-sight so that the UV from the first triggered SG can cause pre-ionization of the remaining gaps to ensure reliability in the simultaneous sparking of all the gaps by reducing the statistical time lag. All the stages are held together by a perspex casing of dimensions $280 \times 280 \times 1500 \mathrm{~mm}$ and mounted on a $10-\mathrm{mm}$ thick aluminum plate supported on wheels. The entire Marx assembly is kept in a metallic case for EMI shielding.

Commercially available high voltage pulse forming line capacitors are used in every stage of the Marx generator (Systech Capacitors (P) Ltd, Bangalore). These capacitors have been tested up to $35 \mathrm{kV}$. These are fast-discharge energy storage capacitors possessing low inductance and high current delivering capability.

SGs for all the stages have been locally fabricated. Each SG consists of two electrodes in the form of spherical balls made of stainless steel. The electrode assembly is held together by a perspex structure; the gap between two balls can be adjusted from 6 to $11 \mathrm{~mm}$ by moving them back and forth with the help of adjustable screws. The SG used in the first stage has an additional feature is having a bore in one of its balls, which is kept at ground potential before switching on. A hollow ceramic tube of $1.2 \mathrm{~mm}$ diameter is inserted though this bore. A $0.5 \mathrm{~mm}$ wire is then inserted through this ceramic tube. This forms an addition terminal $\mathrm{T}$. When a negative $6 \mathrm{kV}$ pulse is applied to the $\mathrm{T}$, a spark is produced between $\mathrm{T}$ end and the ball surface due to close proximity. This spark closes all the SGs when sufficient voltage is present between the two spherical electrodes.

The Marx resistors R's, also known as tail resistors, are used to prevent the Marx capacitors from getting short-circuited when the SGs get fired. They also provide a dump for the energy stored in the capacitors in case of emergency or malfunctioning, and control the shape of the wave tail as per specifications. These resistors are of non-inductive type so as to avoid undesired oscillations in the erected Marx circuit. The maximum voltage drop across $\mathrm{R}$ would correspond to the charging voltage and therefore should have enough insulation at this level to prevent flash-over across the surface of the resistor former. We have fabricated these non-inductive resistors by hand-winding 22-gauge Nichrome wire on a one-mm thick fibre reinforced plastic (FRP) sheet. The length of the used wire is such that the total resistance is $50 \Omega$. Enough insulation and mechanical rigidity is introduced by epoxying these resistors. (Mittal 1986; HPM 1993; Ron 1993).

For measuring high voltages, a shielded copper sulphate $\left(\mathrm{CuSO}_{4}\right)$ resistive voltage divider having divider ratio 1000:1 is used. The construction of this is as follows: The divider consists of two resistors $R_{1}$ and $R_{2}$ connected in series. High voltage is applied to one end of $R_{1}$, while the other end of $R_{2}$ is grounded. Voltage is measured across $R_{2}$. To avoid reflections of measured voltage pulse, we introduce a $50 \Omega$ resistor with one end of $R_{2}$. The resistor $R_{1}$, having value of $1 \mathrm{k} \Omega$, is made up of dilute solution of $\mathrm{CuSO}_{4}$ in de-ionized water filled in a hollow perspex cylinder $300 \mathrm{~mm}$ long and $24.1 \mathrm{~mm}$ in diameter. Increased crosssectional area enhances the non-inductive feature of this resistor. The hollow perspex cylinder acts as a resistor of infinite resistance, which draws infinitesimal current. This suppresses the effect of coupling capacitance with the surroundings and thus makes the resistor $R_{1}$ a shielded resistor. The other resistance $R_{2}$ is made up of 10 non-inductive carbon film resistors, each of value $10 \Omega$, connected in parallel. The effective value is one ohm. The $R_{2}$ resistor assembly is enclosed in an aluminum cylinder having outer diameter $75 \mathrm{~mm}$, inner diameter $66 \mathrm{~mm}$ and length $100 \mathrm{~mm}$. This metallic enclosure for the $R_{2}$ resistor gives an EMI shielding to resistor $R_{2}$. Attenuated signals from this divider are fed to a digital storage oscilloscope. 


\section{Relativistic electron beam generation}

The high voltage terminal of the Manx generator is connected to an REB diode (Miller 1982; Mittal 1986) by a copper strip, $25.4 \mathrm{~mm}$ wide, $3 \mathrm{~mm}$ thick and $750 \mathrm{~mm}$ long. The structure of the REB diode is as follows: A $50 \mathrm{~cm}$ long, $10 \mathrm{~mm}$ diameter stainless steel rod (SS) is insulated by epoxying. The outer surface of the insulator is rippled to inhibit flash-over. The structure is then placed inside a hollow SS cylinder $C_{1}$ of $25 \mathrm{~cm}$ inner diameter and is kept at ground potential. One end of the SS rod is connected to aluminum cathode, while the other end joins the high voltage end of the Marx generator. A blank disc is connected to one end of $C_{1}$. The gap between the cathode and the disc can be varied from 6 to $12 \mathrm{~mm}$. This geometry forms a planar diode. The air is evacuated to a pressure of $\sim 10^{-5}$ Torr. The impression of the beam can be recorded on a thermal paper glued on the blank disc. Beam voltage is measured by introducing a shielded divider between the input to the cathode and the ground.

\section{Results and discussions}

Photographs of an erected Marx generator are shown in figure 2. In figure 2a, the erected MG is unshielded. We were able to measure voltage waveforms from this Marx, after shielding the oscilloscope cable for electromagnetic interference (EMI) with aluminum foil. However, the oscilloscope occasionally turned itself off during some shots. This did not seem to cause any damage. Therefore, further shielding was introduced by enclosing the Marx in an aluminum case. This is depicted in figure $2 b$.

The power delivering capability of the Marx at a given load is dependent on its internal impedance. We obtain this internal impedance by applying the high voltage pulse to various EMI-shielded $\mathrm{CuSO}_{4}$ loads. We have chosen the value of resistances as $85,100,120,150$, 180 , and $200 \Omega$. The voltage across the load, after scaling down by a factor of 1000 by the voltage divider, is further attenuated by a factor of 100 using Tektronics voltage attenuators.

(a)

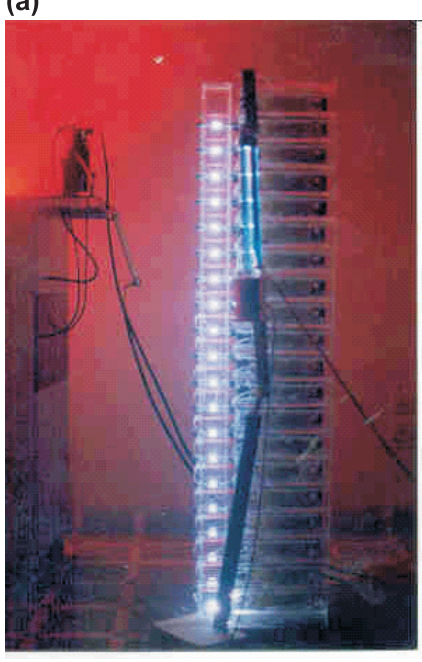

(b)

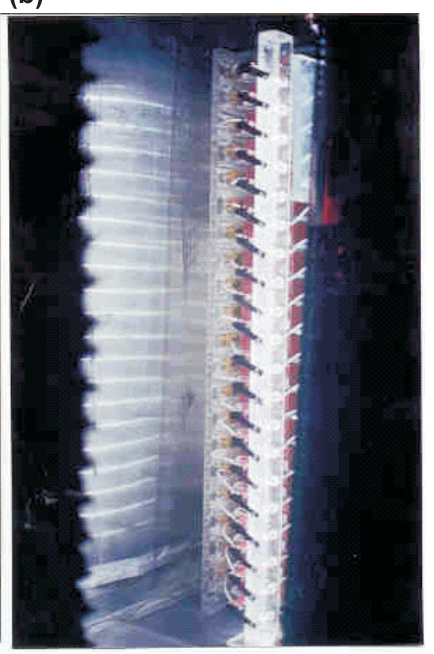

Figure 2. Photographs of the erected Marx generator: (a) unshielded and (b) shielded. 
The attenuated signal is then fed to a $100 \mathrm{MHz}$ digital storage oscilloscope (TDS 220, Tektronics). The corresponding output voltage waveforms are shown in figures $3 \mathrm{a}-\mathrm{f}$. In figure $3 \mathrm{a}$, a maximum pulse voltage of $175 \mathrm{kV}$ together with a voltage reversal of $25 \mathrm{kV}$ is observed. In figure $3 \mathrm{~b}$, a pulse voltage of $\sim 180 \mathrm{kV}$ together with a voltage reversal of $10 \mathrm{kV}$ is observed, while the pulse duration remains almost the same, i.e., $150 \mathrm{~ns}$. The value of the load resistance seems to be quite close to the internal impedance of Marx. In figure 3c, a pulse voltage of $\sim 200 \mathrm{kV}$ together with no voltage reversal is observed. In figures $3 \mathrm{~d}$, $3 \mathrm{e}$ and $3 \mathrm{f}$, pulse voltages of $\sim 220 \mathrm{kV}, \sim 225 \mathrm{kV}$, and $\sim 230 \mathrm{kV}$ respectively, together with over-damped tails of
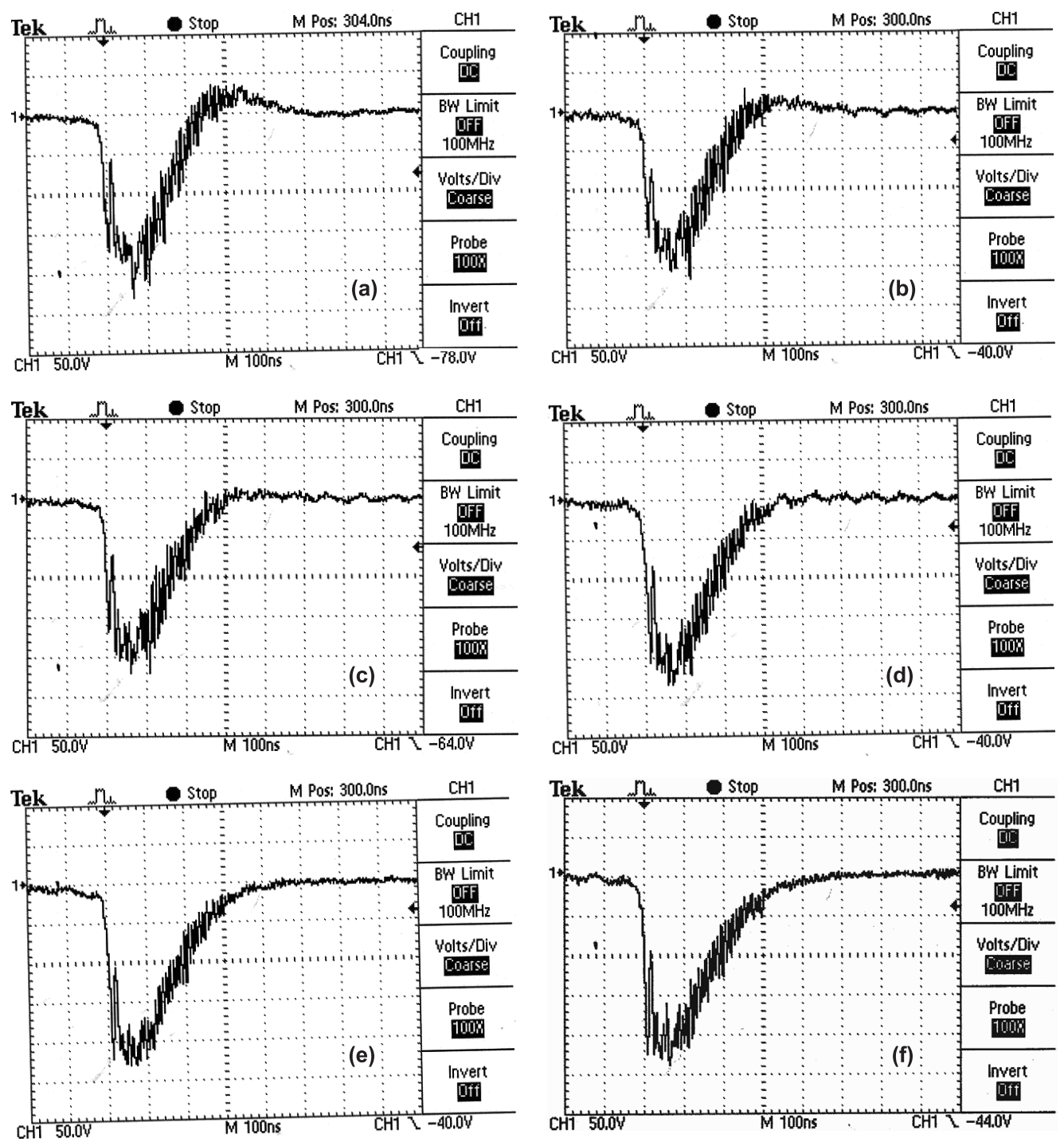

Figure 3. Voltage waveforms for various $\mathrm{CuSO}_{4}$ loads after the voltage is scaled down by a factor of 1000 by a $\mathrm{CuSO}_{4}$ voltage divider and further scaled down by the Tektronics $100 \mathrm{X}$ attenuator. The load values are (a) 80, (b) 100, (c) 115, (d) 150, (e) 180 and (f) $200 \Omega$. 
the pulses are observed. The pulse durations vary from $\sim 150$ to $\sim 200 \mathrm{~ns}$ with increase in the load resistance. We infer that the internal impedance of the Marx generator is about 90-100 $\Omega$.

Once the Marx impedance is known, the output voltage is fed to the REB diode. The beam voltage pulses for various cathode-anode gaps (K-A gaps) are depicted in figures $4 \mathrm{a}-\mathrm{e}$. The signal was taken after rubbing the polished cathode with sand paper. All the pulses show an initial narrow ( $\sim 10 \mathrm{~ns})$ burst in voltage, after which the expected pulse shape is obtained. During the rise of voltage in this burst, the cathode anode gap is open as the plasma has not yet formed. The recorded signal is the voltage across the $1000 \mathrm{k} \Omega$ resistive load, the divider acting as the load. As soon as plasma is formed in the gap, the impedance starts collapsing and reaches a steady value $R_{\mathrm{REB}}$. The beam voltage is therefore obtained after ignoring the
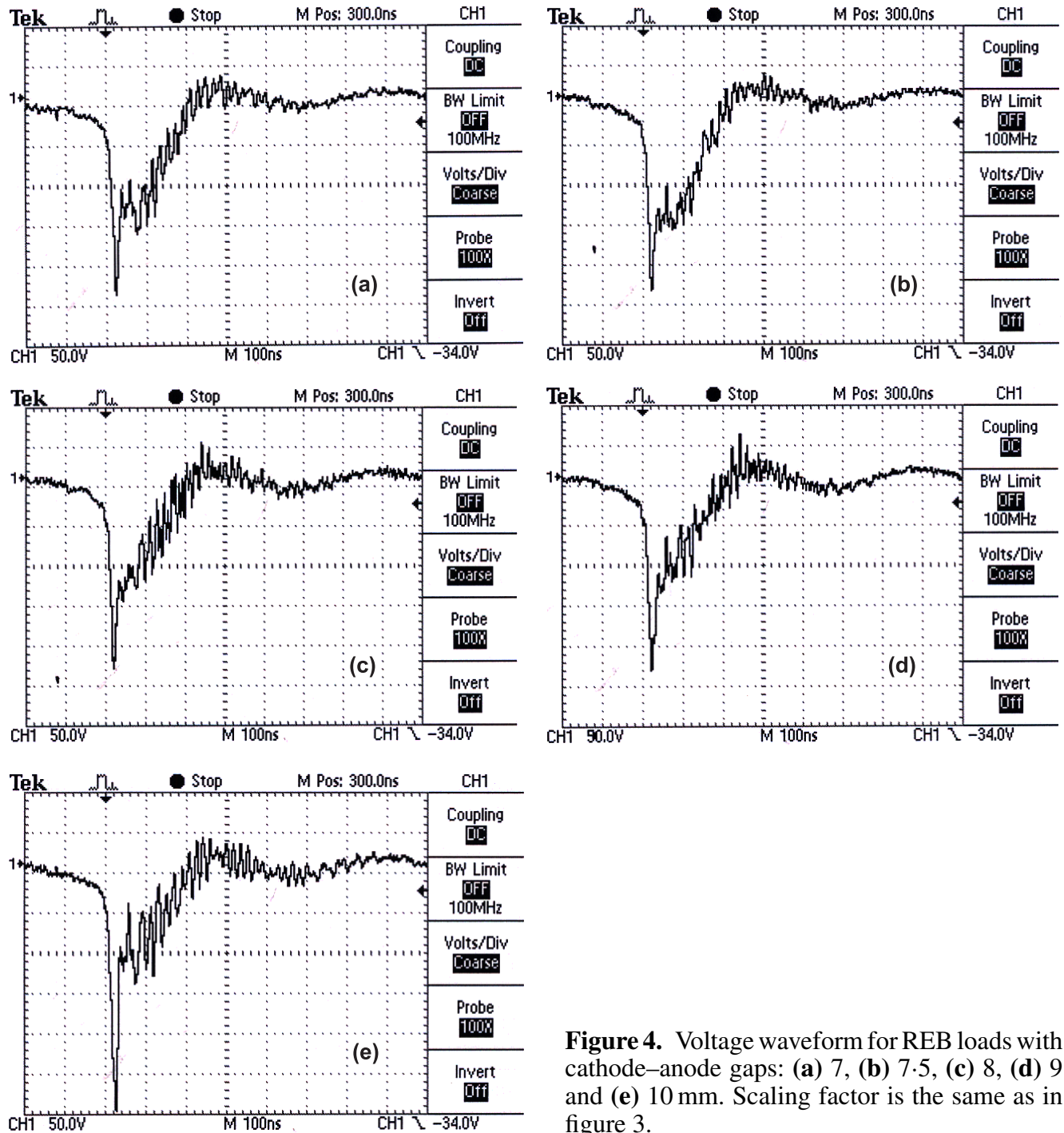

Figure 4. Voltage waveform for REB loads with cathode-anode gaps: (a) 7, (b) 7.5, (c) 8, (d) 9 and (e) $10 \mathrm{~mm}$. Scaling factor is the same as in figure 3 . 
(a)

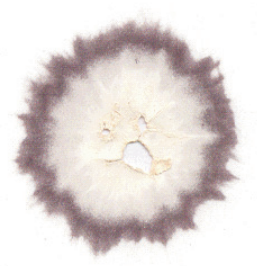

(d)

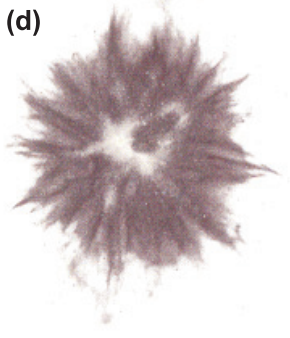

(b)

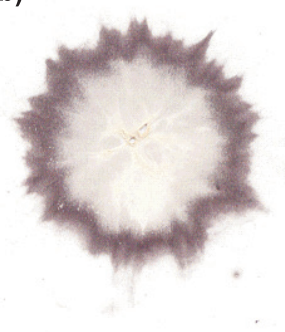

(e)

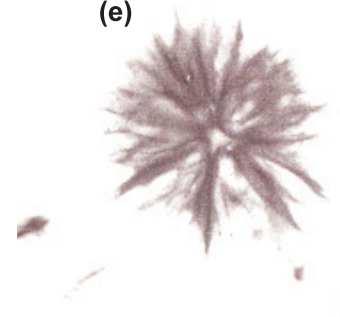

(c)

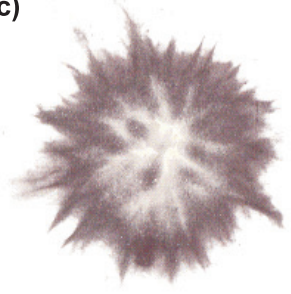

Figure 5. Signature of the solid REB on a heat-sensitive paper for various cathode-anode gaps: (a) 7, (b) 7.5, (c) 8, (d) 9 and (e) $10 \mathrm{~mm}$.

initial narrow pulse. The value of $R_{\mathrm{REB}}$ is dependent on the cathode-anode gap (Miller 1982). The results are depicted in figures $4 \mathrm{a}-\mathrm{e}$. Figure $4 \mathrm{a}$ is plotted when the cathode-anode gap is $7.0 \mathrm{~mm}$. A maximum pulse voltage of $160 \mathrm{kV}$ together with a voltage reversal of $10 \mathrm{kV}$ is observed. The figure $4 \mathrm{~b}$ is drawn for $\mathrm{K}-\mathrm{A}$ gaps of $7.5 \mathrm{~mm}$. The pulse voltage remains $\sim 160 \mathrm{kV}$, though it is much flatter. The pulse duration remains the same as in the previous case, i.e., $150 \mathrm{~ns}$. This case is similar to the voltage waveform for a $100 \Omega \mathrm{CuSO}_{4}$ load depicted in figure $3 \mathrm{~b}$. We conclude that beam impedance is $\sim 90-100 \Omega$ at $7.5 \mathrm{~mm}$ gap. In figures $4 \mathrm{c}$, $4 \mathrm{~d}$ and $4 \mathrm{e}$, the $\mathrm{K}-\mathrm{A}$ gaps are 8,9 and $10 \mathrm{~mm}$ respectively.

In figure 5, signatures of the solid REB on heat-sensitive paper for cathode-anode gaps corresponding to figures $4 \mathrm{a}-\mathrm{e}$ are shown. Figure 5 a corresponds to the voltage trace shown in figure $4 \mathrm{a}$. The white central portion is because of excessive heating. The beam is strongest here. Even the glaze of the heat-sensitive thermal paper has been damaged. A black ring encloses the white portion which implies weaker beam density and then the unaffected area which denotes the cutoff. Figure $5 \mathrm{~b}$ corresponds to the voltage trace shown in figure $4 \mathrm{a}$. A structure similar to figure $5 \mathrm{a}$ is observed, although the beam radius has clearly increased. This is because of divergence of the beam due to strong space charge fields and the absence of a guide magnetic field. The burn pattern shown in figure $5 \mathrm{c}$ corresponds to figure $4 \mathrm{c}$ where the strong central burn has disappeared owing to increase in $R_{\mathrm{REB}}$.

\section{Conclusion}

This paper presents the development of an indigenously developed Marx generator and REB system. The MG is capable of delivering a maximum of $300 \mathrm{kV}$ on a matched load for $30 \mathrm{kV}$ DC charging. The Marx internal impedance is $\sim 90-100 \Omega$. On a matched, shielded, 
non-inductive resistive load, it delivers a voltage pulse of maximum voltage $230 \mathrm{kV}$ and pulse duration $150 \mathrm{~ns}$ at peak current $2 \cdot 2 \mathrm{kA}$ for $25 \mathrm{kV}$ DC charging. The generator is used to produce REB. The beam is capable of driving a backward wave oscillator (BWO) for generating high power microwaves in the power range of couples of megawatts (HPM 1993) and can be used in various experiments like Vircator, free electron lasers (FEL) etc.

Thanks are due to the Board of Research in Nuclear Sciences, Mumbai and the Defence Research and Development Organization, New Delhi for financial support. Thanks are also due to Dr R C Sethi, Accelerator and Pulse Power Division, Bhabha Atomic Research Centre, and his team for assistance in setting up this experiment.

\section{References}

Pai S T, Zhang Q 1989 Introduction to high power pulse technology (Singapore: World Scientific) Granatstein V L, Alexeff I 1987 High power microwave sources (Boston: Artech House)

Mittal K C 1986 Gigawatt pulsed relativistic electron beam generation studies in vacuum and gas filled diodes. $\mathrm{PhD}$ thesis, University of Bombay, Mumbai

HPM 1993 Proc. Workshop on Pulse Power Technology \& High Power Microwaves (HPM-93), Bhabha Atomic Research Centre, Bombay

Ron P H 1993 Private lecture notes on High power pulse technology

Miller R B 1982 An introduction to the physics of intense charged particle beams (New York: Plenum) 